\title{
Descrição e Análise de uma Intervenção Psicológica com Bailarinos pelo Software IRAMUTEQ
}

\author{
Andressa Melina Becker da Silva ${ }^{1^{*}}$ \\ Sônia Regina Fiorim Enumo \\ Programa de Pós-Graduação em Psicologia, Pontifícia Universidade Católica de Campinas, \\ Campinas, SP, Brasil
}

\section{Resumo}

Bailarinos convivem diariamente com a dor, muitas vezes não sabendo como enfrentá-la adequadamente, o que pode comprometer o desempenho físico e sua qualidade de vida. Baseado nisso, foi desenvolvido um programa de intervenção psicológica no coping da dor para bailarinos, com a duração de oito sessões de aproximadamente 45 minutos, aplicado em 14 bailarinas de Jazz, com idade entre 12 e 17 anos $(M=$ $14,63 ; D P=1,42)$, que competem em nível internacional. Assim, objetivou-se neste estudo apresentar a utilização de um software para avaliação do conteúdo apresentado por bailarinos e mediadora em intervenção psicológica. Através do software IRAMUTEQ, realizou-se análises monotemáticas e temáticas em três corpus textuais. Foram feitas a Análise Hierárquica Descendente e Análise de Similitude. Para o primeiro corpus (relatos da mediadora), foram analisados 417 segmentos de texto (ST), retendo 77,70\% desse total, formando 5 classes - Processo sensorial, Registro da dor, Processo de intervenção, Técnicas para controle do estresse, Coping e pós-coping. No segundo corpus (relatos das bailarinas), foram analisados $250 \mathrm{ST}$, retendo-se $73,20 \%$ desse total, formando 5 classes - Desafios no contexto do jogo da dor, Riscos da dança, Dilemas da dor, Treino de imaginação e relaxamento, Ajustamento às opções disponíveis no meio social. Para o terceiro corpus (relatos das bailarinas e da mediadora), foram analisados $667 \mathrm{ST}$, retendo-se $83,96 \%$ desse total, formando 4 classes - Processos de imaginação, Processo de enfrentamento da dor, Técnicas para controle do estresse, Processo de avaliação e intervenção. O software mostrou-se útil e eficaz para análise de conteúdo da intervenção psicológica.

Palavras-chave: Intervenção psicológica, dança, adolescentes, métodos de pesquisa, psicologia do esporte.

\section{Description and Analysis of Psychological Intervention with Dancers by the Software IRAMUTEQ}

\begin{abstract}
Dancers live daily with pain, but often they do not know how to deal adequately with it. Based on this concern, we developed a psychological intervention for dancers to cope with pain, applied to 14 Jazz dancers, aged between 12 to 17 years old $(M=14.63 ; S D=1.42)$, who have been competing internationally. This study presents the use of a software for analysis of the verbal reports of dancers and the mediator presented along the psychological intervention. Using the IRAMUTEQ software, we did the held monothematic and thematic analysis on three textual corpus by Hierarchic Analysis

Endereço para correspondência: Avenida das Pitangueiras, 220, Condomínio Margaridas, Bloco E, Apto. 128, Campinas, SP, Brasil. Fone: (15) 99801-1507. E-mail: andressa_becker@hotmail.com

Financiamento: Coordenação de Aperfeiçoamento de Pessoal de Nível Superior (CAPES); Conselho Nacional de Desenvolvimento Científico e Tecnológico (CNPQ).
\end{abstract}


Descendant and Similarity Analysis. In the first corpus (mediator reports), were resulted in 5 classes Sensory Process, Pain Register, Intervention Process, Techniques for Stress Management, Coping and Post-Coping. In the second corpus (dancer reports), 5 classes - Challenges in the Pain Game, Dance Risks, Pain Dilemmas, Imagery Training and Relaxing, and Adjustment to the Options Available in the Social Environment. In the third corpus (dancers and mediator reports), 4 classes - Imagination Process, Process of Coping with Pain, Techniques for Stress Management, Process of Evaluation and Intervention. The software showed useful and effective for psychological intervention content analysis.

Keywords: Psychological intervention, dance, adolescents, research methods, sports psychology.

\section{Descripción y Análisis de Intervención Psicológica con Bailarines por Software IRAMUTEQ}

\section{Resumen}

Bailarines viven diariamente con el dolor, a menudo no saber cómo lidiar con ella correctamente, lo que puede poner en peligro el rendimiento físico y la calidad de vida. Con base en esto, se desarrolló un programa de intervención psicológica en el dolor para los bailarines, con una duración de ocho sesiones de unos 45 minutos, con 14 bailarines de Jazz, con edades comprendidas entre los 12 a 17 años $(M=$ $14.63 ; D E=1.42$ ), que compiten a nivel internacional. El objetivo de este estudio es presentar el uso de un software para la evaluación del contenido revelado por bailarines y mediador en la intervención psicológica. A través del software IRAMUTEQ, se hizo análisis monotemático y temático sobre tres corpus textuales. Se les hizo análisis de clasificación jerárquico descendente y análisis de similitud. Para el primer corpus (relatos del mediador), se analizaron 417 segmentos de texto (ST), con la retención de $77,70 \%$, y la formación de las clases 5 - Proceso sensorial, Registro de dolor, Proceso de intervención, Técnicas para el manejo del estrés, Afrontamiento y post-afrontamiento. En el segundo corpus (relatos de los bailarines) se analizaron $250 \mathrm{ST}$, retuvieran 73,20\% del total, formando cinco clases - Desafíos en el contexto del juego del dolor, Riesgos de la danza, Dilemas del dolor, Entrenamiento de la imaginación y la relajación, Adaptación a las opciones disponibles en el entorno social. Por tercer corpus (relatos de los bailarines y el mediador) se analizaron $667 \mathrm{ST}$, sosteniendo $83,96 \%$ del total, por lo que 4 clases - Procesos de imaginación, Proceso de afrontamiento del dolor, Técnicas para el manejo del estrés, Proceso de evaluación e intervención. El software demostró ser útil y eficaz para el análisis de contenido de la intervención psicológica.

Palabras clave: Intervención psicológica, danza, adolescentes, métodos de investigación, psicología del deporte.

A intervenção psicológica é uma das formas de atuação profissional do psicólogo visando a alterar comportamentos, pensamentos e emoções, de forma a proporcionar uma melhor saúde e qualidade de vida (Chaves, Vázquez, \& Hervás, 2015; Lipp, 2012; Wright, Sudak, Turkington, \& Thase, 2012). A intervenção psicológica deve ser estruturada conforme a demanda observada pelo uso de avaliação psicológica, bem como pelo referencial teórico utilizado pelo mediador. Além disso, é possível aplicar uma intervenção psicológica em dife- rentes contextos, como em hospitais (Alcântara, Shioga, Lima, Lage, \& Maia, 2013; Motta \& Enumo, 2010; Pfeifer \& Ruschel, 2013), escolas (Lopes \& Almeida, 2015; Souza et al., 2014), empresas (Leandro-França, Murta, \& Villa, 2014; Lino \& Ziliotto, 2013), assim como em instituições esportivas e de prática de atividade física (Godtsfriedt, Andrade, \& Vasconcellos, 2014; Heaney, Walker, Green, \& Rostron, 2015; Larsen \& Henriksen, 2015; Markland, Hall, Duncan, \& Simatovic, 2015; Weinberg \& Gould, 2014). 
Considerando especificamente as intervenções em Psicologia do Esporte e da Atividade Física, percebe-se ser esta uma área relativamente recente dentro da Psicologia, que vem ganhando destaque no Brasil em decorrência dos grandes eventos esportivos, como a Copa do Mundo de Futebol e os Jogos Olímpicos (Vieira, Vieira, \& Nascimento, 2013). Em sua prática profissional, o psicólogo do esporte e da atividade física tem, entre outras atividades, o papel de avaliar os fenômenos individuais e grupais que interferem no rendimento esportivo, na saúde e na qualidade de vida dos participantes, em sua personalidade e temperamento. Deve também atentar para as demandas psicológicas exigidas para a execução de determinados movimentos, considerando a etapa de treinamento a qual o indivíduo se encontra (Andersen, 2011; Weinberg \& Gould, 2014). Após essa avaliação, poderá selecionar qual intervenção será mais adequada.

Apesar de não ser considerada uma modalidade esportiva, a dança apresenta aspectos em comum, como, por exemplo, a carga intensa de treinamento físico e as competições (Guarino, 2015). Assim, os grupos de dança deveriam ter a presença de um psicólogo qualificado em atividade física em seu quadro de funcionários, visando à integridade dos bailarinos e da equipe que os acompanha.

Após a avaliação psicológica, o psicólogo do esporte e da atividade física escolherá qual o melhor método de intervenção para os bailarinos, considerando o que deverá abordar na intervenção. Podem ser aplicados instrumentos de avaliação antes e após a intervenção e, caso ocorram diferenças significativas entre os resultados, estas podem ser consideradas indicadores de alterações psicológicas.

Um constructo psicológico possível de ser estudado na dança é a dor, considerando que os bailarinos convivem diariamente com sintomas álgicos devido à intensa carga de treinamento, com curtos intervalos de recuperação (Singh, 2011). Saber como enfrentar esse estressor - a dor -, é fundamental para que os bailarinos consigam diminuir a percepção de dor, sua intensidade e frequência, bem como apresentar melhor desempenho técnico/físico e qualidade de vida (Encarnación, Meyers, Ryan, \& Pease, 2000).

Essas questões levaram à proposição de um programa de intervenção no coping (enfrentamento) da dor para bailarinos adolescentes, cujos dados estão descritos em parte neste artigo. Adotou-se uma abordagem desenvolvimental do coping, proposta pela Teoria Motivacional do Coping [TMC] como um processo de autorregulação em condições de estresse, em que as estratégias de enfrentamento (ways of coping) seriam aprimoradas e diferenciadas ao longo do ciclo de vida (Ramos, Enumo, \& Paula, 2015; Skinner, Edge, Altman, \& Sherwood, 2003; Skinner \& Wellborn, 1994). Na TMC, o coping é um constructo que descreve como as pessoas regulam seus próprios comportamentos, emoções e orientações motivacionais sob condições estressantes. Este processo envolve esforços individuais para manter, restaurar e reparar três necessidades psicológicas básicas de Relacionamento, Autonomia e Competência.

A TMC propõe uma análise do coping com base em uma estrutura hierárquica, em que há instâncias ou comportamentos de coping (categorias de baixa ordem) que podem ser agrupados conforme sua funcionalidade em "estratégias de enfrentamento". Estas, por sua vez, também têm funções semelhantes e podem ser agrupados em famílias de coping (categorias de alta ordem). Quando o estressor é visto como um desafio ao self ou ao contexto, têm-se seis famílias de coping adaptativas: Autoconfiança e Busca de Suporte (relacionadas à necessidade de Relacionamento), Resolução de Problemas e Busca de Informações (necessidade de Competência), Acomodação e Negociação (necessidade de Autonomia). Se o estressor é visto como uma ameaça ao self ou ao contexto, podem ocorrer uma dessas seis famílias mal adaptativas: Delegação e Isolamento (necessidade de Relacionamento), Desamparo e Fuga (necessidade de Competência), Submissão e Oposição (necessidade de Autonomia; Skinner et al., 2003).

Para os dados desse programa de intervenção em foco, foi colocada a seguinte questão: "Como descrever e analisar a interação ocorrida durante um programa de intervenção no coping 
da dor para bailarinos adolescentes?" Considerou-se, então, relevante analisar o conteúdo verbal apresentado pelos participantes, bem como os relatos verbais do psicólogo durante essa mediação. Esta seria uma forma de apreender o processo de intervenção, buscando identificar variáveis explicativas para as mudanças associadas ao processo interventivo. Esta questão tem sido pouco discutida metodologicamente, havendo poucos instrumentos validados, especializados aplicados no estudo da atividade física. Assim, este estudo descreve a utilização de um software para avaliação do conteúdo verbal apresentado por bailarinos e pela mediadora em contexto de intervenção psicológica no coping da dor.

\section{Método}

\section{Participantes e Fontes de Dados}

Os dados aqui analisados foram coletados durante um programa de intervenção no coping da dor, com oito sessões mediadas pela pesquisadora principal. Esta tem formação em Educação Física e Psicologia, em nível de graduação e pós-graduação, além da formação técnica em ballet clássico e sapateado, atuando há 23 anos como bailarina (inclusive de Jazz) e como professora de dança há oito anos.

O Programa de Intervenção no Enfrentamento da Dor em Bailarinos - PIEDOR-Bailarinos - foi baseado nas propostas de Caudill (1998), Gould, Damarjian e Greenleaf (2011) e de Stefanello (2007) para intervenção em atletas e pessoas com dor crônica. A proposta desse Programa surgiu pela experiência da pesquisadora principal na área, constatando a falta de intervenções psicológicas em bailarinos, apoiada em resultados prévios de avaliações psicológicas nessa população, mostrando um agravamento do quadro de dor e a presença de estratégias de enfrentamento mal adaptativas. Assim, baseando-se em intervenções já existentes para atletas, buscou-se desenvolver um método que pudesse ser aplicado em bailarinos, no próprio espaço de ensaios, e que fosse elaborado e aplicado por psicólogos.

O programa de intervenção foi realizado em oito sessões, com uma duração aproxima- da de 45 minutos cada, uma vez por semana. Como a rotina de atletas e bailarinos tem muitas atividades e os treinadores e professores limitam as interrupções e intervenções nos grupos, considera-se mais adequada a realização de programas interventivos breves. As sessões foram realizadas entre agosto e outubro de 2014, logo após o período competitivo dessa área. $\mathrm{O}$ objetivo geral do programa foi desenvolver, por meio de técnicas de imaginação, estratégias de enfrentamento da dor mais adaptativas em longo prazo. Foram realizadas atividades, como imaginar situações na dança e de dor em que as bailarinas imaginam um formato para a dor e depois a alteram mentalmente, demonstrando que pode haver um controle cognitivo e emocional sobre a mesma, além de reestruturação cognitiva e relaxamento.

Ao longo das sessões, foram utilizados alguns materiais, como: (a) Folheto de Psicoeducação; (b) Questionário Subjetivo de Avaliação da Capacidade Imaginativa (Gould, Damarjian, \& Greenleaf, 2011); (c) Questionário para Imaginação na Dança (Martens, 1987; Vealey, 1991; adaptado livremente pela pesquisadora para bailarinos), a versão para bailarinos foi necessária, tendo em vista que existem termos específicos da dança, por exemplo, o item 3 do instrumento - "Dançando em um Festival" como substituto de "Jogando em uma Competição", usada na versão para atletas; (d) Diário de dor e de medicação- com perguntas sobre intensidade, local e frequência da dor, uso de medicação e de estratégias de enfrentamento, se há doença que agrava ou justifica a dor e o tipo e duração de prática de atividade física no dia;( e) Jogo de Tabuleiro - que objetiva a psicoeducação sobre estratégias de enfrentamento e o reconhecimento do coping adaptativo e mal-adaptativo; (f) Questionário de satisfação do usuário - adaptado de Ramos (2012), contendo cinco perguntas fechadas e duas discursivas. Em etapa de pré-teste e pós-teste, foi aplicada também uma bateria de avaliação psicológica para os constructos - estresse e estressores (medidas subjetivas e objetivas, como a medida do cortisol capilar e salivar e do ácido lático sanguíneo), ansiedade, dependência de exercício físico, autoeficácia, coping 
da dança, coping da dor e qualidade de vida. Esses dados sobre os efeitos da intervenção não serão abordados neste artigo.

Participaram do estudo 14 bailarinas da modalidade de $J a z z$, com idade entre 12 e 17 anos $(M=14,63 ; D P=1,42)$, que competiam em nível nacional e internacional. Foram selecionadas por apresentarem alto nível competitivo, ganhando diversas premiações nos festivais nacionais e internacionais dentro dessa modalidade e faixa etária, tendo em vista as premiações que o grupo ganhou em importantes festivais de dança. Ensaiavam em média 4h30min nos dias de semana e mais $2 \mathrm{~h}$ aos sábados, além de aulas extras, como ballet clássico e contemporâneo, jazz e hip hop. Dançavam em média há sete anos e competiam em média há quatro anos. Essas bailarinas frequentavam uma Escola de Dança na cidade de Curitiba, PR, constituindo uma amostra por conveniência. Todas relataram sentir dor.

\section{Aspectos Éticos}

Todos os aspectos éticos foram seguidos conforme a Resolução 466/2012 do Conselho Nacional de Saúde. O estudo foi aprovado em Comitê de Ética para Pesquisa com Seres Humanos sob o Parecer número 783.537; CAAE: 23756113.3.0000.5481. As bailarinas só participaram após assinatura do Termo de Consentimento Livre e Esclarecido pelos pais e assinatura do Termo de Assentimento, assinada por elas próprias demonstrando interesse em participar da pesquisa.

\section{Procedimentos e Análise de Dados}

Realizou-se a transcrição de cada sessão de intervenção e após foram separados os relatos verbais das bailarinas (grupo) e da mediadora (psicóloga do esporte). As análises feitas pelo software são consideradas qualitativas, tendo em vista que analisam as palavras utilizadas no discurso, bem como quantitativas, pois são analisadas pela frequência e pelo método estatístico inferencial do Qui-Quadrado. Além disso, é importante destacar que, para a análise ser mais precisa, é necessário haver um volume substan- cial de texto, assim, não seria possível separar os relatos de cada bailarina individualmente, considerando que algumas falam mais do que outras, assim, optou-se por agrupar a fala de todas, assumindo uma integridade grupal.

Posteriormente, organizou-se o material textual decorrente da entrevista em três corpus separadamente. Segundo Camargo e Justo (2015; <www.laccos.com.br>), existem duas maneiras de preparar as linhas de um corpus: a monotemática e a temática, a qual se distingue pela possibilidade da segunda utilizar mais de um tema na mesma análise. Assim, realizou-se uma análise dos relatos das bailarinas, outra dos relatos da mediadora e por último um corpus com os dois temas (bailarinas e mediadora), em duas subtemáticas distintas. Essa divisão foi realizada a fim de compreender melhor as relações entre as verbalizações das bailarinas e da mediadora.

O conteúdo textual contido nesses três corpus foram submetidos à Análise Hierárquica Descente (CHD) e à análise de similitude, por meio do software IRAMUTEQ (Camargo \& Justo, 2013, 2015; Ratinaud, \& Marchand, 2012). Segundo Camargo e Justo (2015), o IRAMUTEQ permite fazer diferentes formas de análises estatísticas sobre corpus textuais e sobre tabelas de indivíduos, por palavras. Com isso, o software contribui para os estudos em Ciências Humanas e Sociais, as quais usam o conteúdo simbólico como uma fonte importante de dados de pesquisa. Além disso, as questões sociodemográficas foram submetidas à análise descritiva no software SPSS (Statistical Package for the Social Science - Pacote Estatístico para Ciências Sociais), versão 20.0.

\section{Resultados}

O primeiro corpus analisado pelo software IRAMUTEQ continha os relatos verbais da mediadora, em uma análise monotemática. A partir da Classificação Hierárquica Descendente (CHD), foram analisados 417 segmentos de texto (ST), retendo-se $77,70 \%$ do total, os quais geraram cinco classes. Inicialmente, o software dividiu o corpus em dois subcorpus: 
1. Processo Sensorial - composto pela classe 1 , incluindo o processo sensorial da imaginação;

2. Processo de Estresse, Coping e seu Manejo - formado pelas classes 2, 3, 4 e 5, relacionado às técnicas para controle do estresse, processo de intervenção, registro da dor e coping e pós-coping. O software ainda dividiu esse subcorpus novamente, opondo a classe 5 às classes 2,3 e 4 . Por fim, houve uma última divisão, em que se opôs a classe 4 , às classes 2 e 3 . (Figura 1).

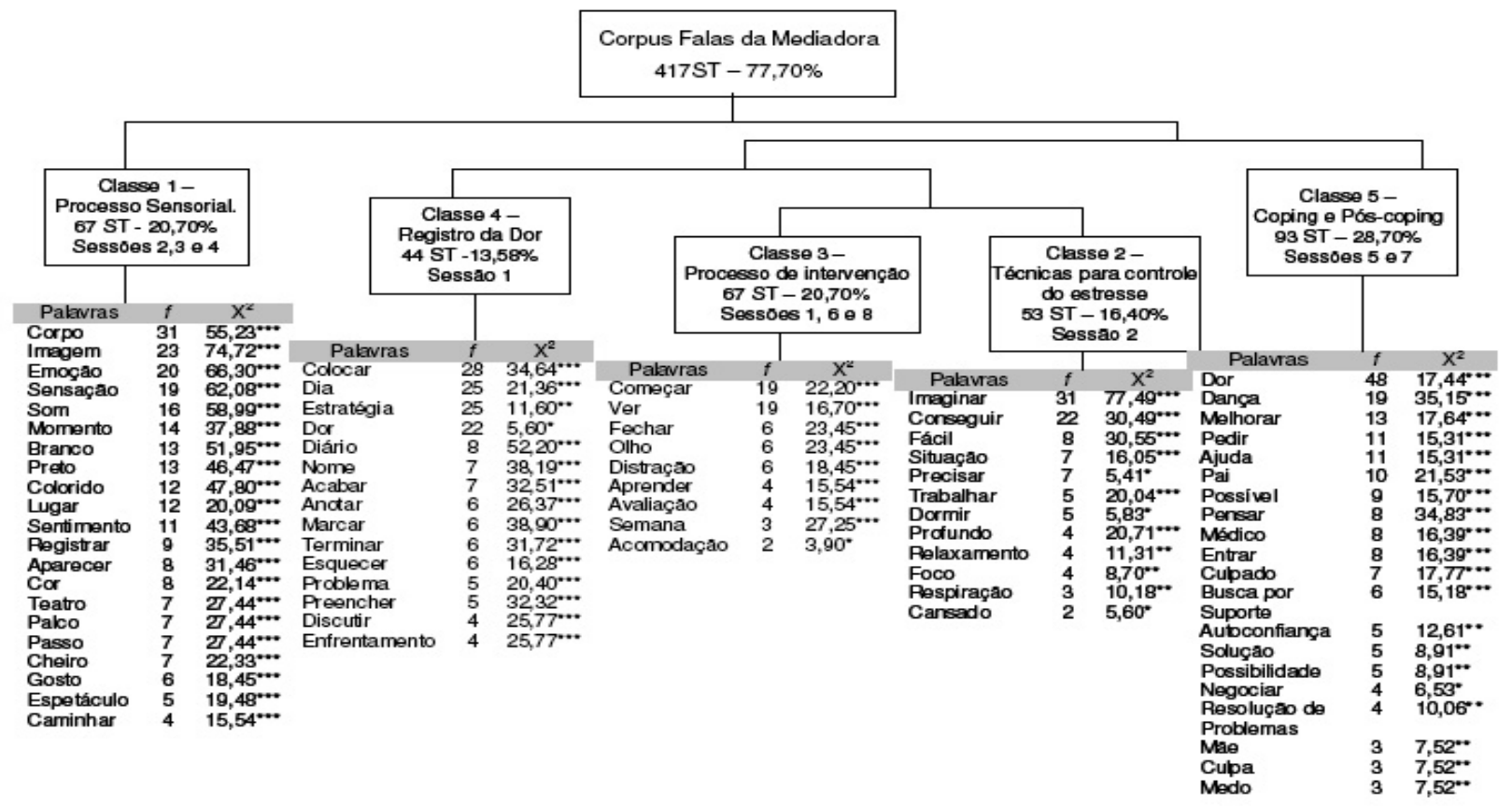

Figura 1. Análise dos relatos da mediadora durante programa de intervenção no coping da dor em bailarinas pelo método de Classificação Hierárquica Descendente.

Nota: ${ }^{*} \mathrm{p}<0,05 ; * * \mathrm{p}<0,01 ; * * \mathrm{p}<0,0001$, teste Qui-Quadrado, software IRAMUTEQ.

A classe 1, chamada de "Processo Sensorial da Imaginação" foi responsável por 20,70\% dos segmentos de texto. Os principais elementos (palavras) que se relacionaram a esta classe foram: espetáculo, teatro, palco, passo, registrar, sentimento, colorido, branco, preto, som, cheiro, emoção, sensação, gosto, imagem, corpo, entre outros (Figura 1). O conteúdo da classe 1 trata principalmente de condições sensoriais necessárias para que o processo de imaginação ocorra. Os trechos a seguir ilustram esse contexto:

"O sinal do teatro deu o primeiro toque, faltam dez minutos. Como está o seu corpo nesse momento? Que sensações aparecem?" (Sessão 7- S7);

"Se perceba fazendo cada movimento dessa coreografia. Que sons isso tem? Como está o seu corpo nesse momento? Está tudo colorido ou preto e branco?" (S3).
A classe 5 intitulada de "Coping e Pós-coping” foi responsável por $28,70 \%$ dos segmentos de texto. Os principais segmentos relacionados a esta classe foram: dança, negociar, possivel, pensar, pedir, ajuda, melhorar, dor, mãe, pai, culpa, medo, resolução de problemas, autoconfiança, busca por suporte, médico, solução, possibilidade, entre outros (Figura 1). O conteúdo desta classe representa a utilização ou não de estratégias de enfrentamento adaptativas e suas repercussões. Os trechos a seguir representam esse contexto:

"Eu não vou compartilhar com meus pais porque se eu falar eles vão me tirar da dança, eu não vou compartilhar com meus colegas de dança porque não sei o que eles vão pensar de mim" (S5);

"Vocês conseguem perceber que cada vez que vocês adiam a ida ao médico, pior é ..." 
(S5); "Medo de não conseguir dançar, medo de se machucar de verdade, medo do que pode acontecer..." (S5);

"Imaginem que você está passando por essa situação de dor e aos poucos você vai se percebendo com uma autoconfiança forte, sentindo que essa dor não pertence a você" (S7).

A classe 4, denominada de "Registro da Dor", foi responsável por $13,58 \%$ dos segmentos de texto. Os principais elementos relacionados a esta classe foram: Discutir, enfrentamento, preencher, marcar, diário, anotar, problema, esquecer, colocar, dia, estratégia, entre outros (Figura 1). O conteúdo desta classe retrata o processo envolvido no preenchimento do diário da dor, como uma forma de registro da dor. Isso as auxilia a visualizar os antecedentes da dor, qual estratégia de enfrentamento utilizada, e o pós-coping, ou seja, a avaliação sobre a funcionalidade de tais estratégias de enfrentamento para alívio da dor, servindo como um material psicoeducativo, de autocontrole e autorregulação. Os trechos a seguir demonstram esse contexto:

"Isso é um diário da dor, ele é como um diário mesmo. A ideia é que todos os dias que vocês estiverem com dor, enquanto a gente estiver fazendo esse projeto de intervenção, é que vocês anotem" (S1);

"O que eu tenho percebido é que muita gente está com dor. Se isso trouxer algum tipo de dor, sim, então anota. Lembra o que eu falei que pode ser qualquer tipo de dor" (S5);

"Não esqueçam de anotar sempre que tiver dor ..." (S4).

A classe 2, denominada por "Técnicas para Controle de Estresse", foi responsável por $16,36 \%$ dos segmentos de texto. Os principais elementos que se relacionaram a esta classe foram: respiração, trabalhar, relaxamento, foco, cansado, imaginar, dormir, entre outros (Figura 1). O conteúdo desta classe retrata o cansaço e formas de controlar o estresse, como com o auxílio da respiração, do relaxamento e da imaginação. Os trechos que expressam esse contexto são apresentados a seguir:

"Fui só falando para vocês irem relaxando as partes do corpo, mas quando você trabalha a respiração junto, ajuda muito a relaxar. Só o próprio fato de relaxar às vezes já ajuda a diminuir a dor" (S2);

"Vocês conseguiram perceber a diferença de hoje quando a gente fez o relaxamento para semana passada que não tinha o relaxamento antes? Conseguiram perceber se foi mais fácil? A tendência é ficar mais fácil"' (S2);

"Vai se distrair ao máximo para não ficar com o foco na dor, ela tende a diminuir. . ." (S5).

A classe 3, chamada de "Processo de Intervenção" foi responsável por $20,68 \%$ dos segmentos de texto. Os principais elementos relacionados a esta classe foram: aprender, avaliação, distração, acomodação, começar, questionário, entre outros (Figura 1). O conteúdo desta classe retrata todo o processo de intervenção, desde a avaliação até o ensinamento de estratégias de enfrentamento adaptativas, como a Acomodação e a Distração. Os trechos a seguir ilustram esse contexto:

"Bom, vocês sabem do processo de pesquisa que eu estou fazendo e tudo mais. A gente fez a parte de avaliação antes justamente para eu ver como vocês estavam" (S1);

"Eu vou vir no final do ano...eu preciso ver ao certo se eu venho em novembro ou dezembro para fazer uma última avaliação com aqueles questionários, tudo de novo" (S8).

Analisando o dendograma e o conteúdo obtido pela análise desse primeiro corpus (Figura 1 ), verifica-se o quanto a mediadora estava orientada para cumprir os objetivos da intervenção, ressaltando todo o processo proposto para modificar o coping da dor. Enfatizou desde a avaliação psicológica, o registro da dor no Diário da Dor, até à intervenção propriamente dita, com enfoque no relaxamento, na imaginação, na psicoeducação, e na discussão para conscientização da importância de se utilizar estratégias de enfrentamento adaptativas ao invés de mal adaptativas.

O segundo corpus apontado pelo software IRAMUTEQ foi sobre os relatos das bailarinas. A partir da Classificação Hierárquica Descendente (CHD), foram analisados 250 segmentos de texto (ST), retendo-se $73,20 \%$ do total, e ge- 


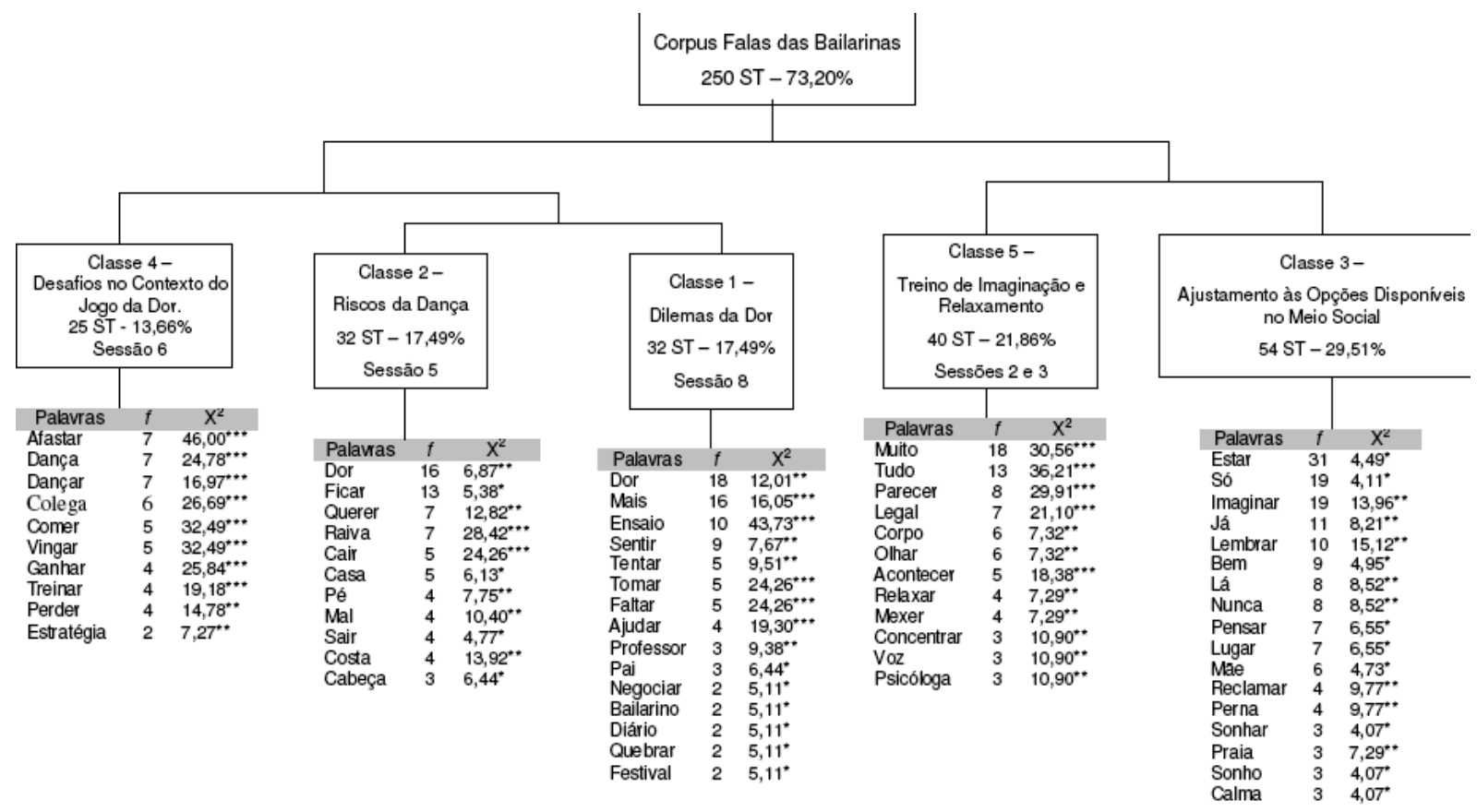

Figura 2. Análise dos relatos das bailarinas durante programa de intervenção no coping da dor em bailarinas pelo método de Classificação Hierárquica Descendente.

Nota: $* p<0,05 ; * *<0,01 ; * * p<0,0001$, teste Qui-Quadrado, software IRAMUTEQ.

rando cinco classes. O software dividiu o corpus Falas da Mediadora em dois subcorpora (Figura 2).

O primeiro subcorpus dos relatos das bailarinas, denominado de "Manejo de Estresse", foi composto pelas classes 3 e 5 . Apresenta relatos sobre como as bailarinas lidam com estressores sociais, da dança, incluindo fazer relaxamento e usar a imaginação. O manejo de estresse é a classe 3 , indicativa do ajustamento às opções disponíveis no meio social, e a classe 5 , do treino de imaginação e relaxamento. $\mathrm{O}$ segundo $s u b$ corpus, denominado de "Intervindo no Contexto da Dor", é formado pelas classes 1, 2 e 4, se relacionam pelos desafios para o uso do coping adaptativo, que inclui os desafios no contexto do jogo da dor, riscos da dança e dilemas da dor. Os dados se reorganizaram em um segundo plano, "Desafios para o Uso do Coping Adaptativo", opondo a classe 4 - Desafios no Contexto do Jogo da Dor às classes 1 - Dilemas da Dor e 2 - Riscos da Dança. Por fim, houve uma última divisão, em que se opôs a classe 1 - Dilemas $d a$ Dor à classe 2 - Riscos da Dança, sendo denominada "Dor e Dança: Relações entre Autonomia e Competência" (Figura 2).
Na primeira partição, a classe 3, incluída no corpus "Manejo de Estresse" pelas bailarinas, denominada de "Ajustamento às Opções Disponíveis no Ambiente Social", foi responsável por $29,51 \%$ dos segmentos de texto. Os principais elementos relacionados a esta classe foram: praia, reclamar, perna, lembrar, sonhar, sonho, calma, lá, nunca, lugar, pensar, mãe, imaginar, estar, só, entre outros (Figura 2). O conteúdo desta classe retrata o quanto elas podem se imaginar em outros contextos prazerosos, como praia, para esquecer a dor, ou mesmo utilizar a respiração para ajudar. Além disso, precisam se ajustar ao fato de não ter o suporte necessário em casa, com medo que a mãe a retire da dança, muitas vezes preferindo ficar só, ao contrário das mães que foram bailarinas e que compreendem melhor a situação, caso que acontece com 3 participantes. Os trechos a seguir ilustram esse contexto:

"Eu imaginei que eu estava indo para praia", "também para praia", "praia", "praia" (S2);

"Metade eu ouvi você falando, metade não, eu só lembro de você falando da boca, depois eu comecei a sonhar" (S4); 
"A gente estava lá em Joinville se aquecendo e a E falou para a gente respirar fundo e relaxar, e ela foi levantando algumas pernas e foi bem mais" (S2);

"Eu imaginei que cheguei em casa e pedi ajuda prá minha mãe, eu imaginei que eu estava chorando, morrendo de dor, e ela me disse que iria me tirar da dança" (S7);

A classe 5, incluída no corpus "Manejo de Estresse" pelas bailarinas, chamada de "Treino de Imaginação e Relaxamento", continha $21,86 \%$ dos segmentos de texto. Os principais segmentos relacionados a esta classe foram: concentrar, voz, psicóloga, acontecer, parecer, legal, relaxar, mexer, corpo, olhar, entre outros (Figura 2). O conteúdo desta classe representa a associação do relaxamento para aperfeiçoar o treino de imaginação, o que exige concentração, o tom de voz utilizado pela psicóloga, e todo o processo em si. Os trechos a seguir ilustram esse contexto:

"Eu não conseguia me concentrar direito, mas depois foi indo... você foi falando e eu fui relaxando totalmente" (S2);

"Eu não tinha muito controle e consegui imaginar bem a apresentação, foi legal!" (S3);

"Consegui imaginar o que eu não conseguia de depois consegui fazer, foi bom, foi bem legal, porque eu não conseguia antes" (S4);

"Acho que aqui a gente relaxou, descansou, consegui me imaginar com uma roupa, e indo pro teatro com outra, consegui imaginar como se nada tivesse acontecido antes, sabe...não sei explicar" (S2).

Opostamente a elas, a classe 4 , parte do corpus "Intervindo no Contexto da Dor" pelas bailarinas, nomeada de "Desafios no Contexto do Jogo da Dor", foi responsável por $13,66 \%$ dos segmentos de texto. Os principais elementos relacionados a esta classe foram: Comer, ganhar, vingar, afastar, treinar, colega, estratégia, dança, dançar, entre outros (Figura 2). O conteúdo desta classe retrata os assuntos mais discutidos durante o Jogo da Dor (S6), durante as cartas "desafios". Foi possível ver o quanto há um rigoroso controle alimentar, o que é considerado um fator de risco para os Transtornos Alimentares, associado com a fraqueza e dor - "Se você parar de comer... não, se a pessoa está se sentindo gorda, ela pode fazer uma dieta" (S6). Há relatos sobre se afastar de colegas para treinar por conta própria, sobrecarregando o corpo e trazendo mais dor:

"Se afastando de uma coisa que não tem nada a ver, porque, se você quiser ensaiar mais, é por sua conta, não tem nada a ver com o grupo" (S6);

"Na minha opinião não tem nada de errado ali, de treinar em outros horários, se você quer melhorar" (S6).

Observa-se que não têm coragem de se vingar de pessoas que assumem o seu papel na coreografia, caso haja uma lesão comprometedora, mas isso gera uma profunda chateação - "Eu não iria me vingar porque meus colegas de dança não são colegas, são amigos verdadeiros" (S6). Sobre o acidentar-se antes do espetáculo e precisar ser substituída: "Eu acho que eu ia ficar triste porque eu não ia poder dançar, eu ia ficar com um pouco de raiva" (S6). Além disso, o quanto elas desejavam ganhar o jogo, revelando alta competitividade, que durante o momento lúdico do jogo era permitido, sem recriminações - " $E$ como que ganha?", "Porque só ela ganha? Eu também respondi! Que injusto! Nossa que sacanagem!" - enquanto isso as colegas do grupo dizendo: "Perde! Perde! Perde!" (S6).

A classe 1, incluída no corpus "Intervindo no Contexto da Dor" pelas bailarinas, foi chamada de "Dilemas da Dor" foi responsável por $17,49 \%$ dos segmentos de texto. Os principais elementos que se relacionaram a esta classe foram: ajudar, tomar, faltar, ensaio, negociar, professor, bailarino, diário, quebrar, festival, pai, tentar, sentir, dor (Figura 2). O conteúdo desta classe trata principalmente das dificuldades de negociar com o professor por ensaios mais leves, por estar com dor, o medo de faltar aos ensaios e de falar para os pais que está com dor, com medo de ser tirada do grupo de dança e não poder participar dos festivais. Os trechos a seguir ilustram esse contexto:

"Eu não falto ensaio, a não ser de eu quebrar o pé assim e não conseguir ensaiar mesmo" (S6); 
"Negocio com o professor para fazer ensaios mais leves. Essa a P não ia concordar... eu nem tento"

(S6); "A solução foi pedir ajuda à outra pessoa para me ajudar a não sentir mais dor" (S7).

A classe 2, parte do corpus "Intervindo no Contexto da Dor" pelas bailarinas, denominada de "Riscos da Dança", foi responsável por $17,49 \%$ dos segmentos de texto. Os principais elementos que se relacionaram a esta classe foram: cair, raiva, costa, mal, cabeça, casa, pé, sair, querer, ficar, dor, entre outros (Figura 2). O conteúdo desta classe retrata o quanto a dança está vinculada à dor e o risco que as bailarinas enfrentam de se machucar e de ter que sair do grupo, o que gera raiva e frustração, inclusive pela falta de compreensão dos amigos e familiares que não são do ambiente da dança. Os trechos a seguir ilustram esse contexto: "Eu tenho raiva quando eu tenho muita dor e alguém vem me irritar, eu tenho vontade de bater. ..." (S5).

Ao se referir a uma possível substituta, caso venha a se machucar:

"Eu acho que se eu visse ela eu não trataria ela mal, só que por dentro, no momento da rai$v a$ é uma chateação, acho que no momento da raiva, quando eu descobrisse que era ela" (S6);

"Acho que hoje a sala inteira está com dor, eu também estou com muita dor aqui e nas costas" (S5).

Relativo ao desamparo de não encontrar mais solução para a dor:

"Ás vezes eu sinto isso para a dor nas minhas costas, porque eu penso que eu vou curar ela, mas ela vai machucar de novo, então eu acho que não vale a pena mexer nela" (S5);

"Mesmo quando você está com dor você vai ter que fazer, vai ter que sair ... às vezes não tem o que fazer" (S6).

Analisando o dendograma e o conteúdo obtido pela análise desse segundo corpus (Figura 2), verifica-se o quanto a dança está associada à dor e a ameaça que a dor e uma possível lesão impõem à competência das bailarinas. Além disso, há uma ameaça à necessidade de autonomia, pois a bailarina não pode compartilhar com os pais sua dor, com medo que os mesmos lhe tirem da dança, assim como não podem procurar um médico, com receio que o mesmo lhe faça pa- rar de dançar por um tempo indeterminado. $\mathrm{Ou}$ seja, suas vidas muitas vezes acabam ficando sob a responsabilidade e decisão de outras pessoas. Além disso, os colegas que não pertencem ao contexto da dança não compreendem o porquê de tantos ensaios, nem porque vivem com dor, afetando, assim, o relacionamento. Frente a esse contexto, percebe-se que elas utilizavam mais estratégias de enfrentamento mal adaptativas do que adaptativas. Este cenário aos poucos foi sendo adaptado e transformado com a intervenção psicológica, com os treinos de imaginação e o processo psicoeducativo. O Jogo da Dor teve uma representatividade tão grande para as bailarinas, que acabou formando uma classe só para ele - Classe 4, pela análise CHD (Figura 2). Isso demonstra que ele poderia ter sido empregado em mais de uma sessão, e o quanto a utilização de um recurso lúdico psicoeducativo é importante, não só para crianças, mas também para adolescentes.

A última análise realizada foi a temática comum aos relatos da mediadora e das participantes em um único corpus, porém, cada uma delas continuando como uma temática (Figura 3). O corpus temático, a partir da Classificação Hierárquica Descendente (CHD), analisou 667 segmentos de texto (ST), retendo-se $83,96 \%$ do total, e gerando quatro classes. O software dividiu o corpus temático em dois subcorpora (Figura 3).

O primeiro subcorpus, denominado de "Intervindo no coping da dor", composto pela classe 4 - "Processos da Imaginação" -, apresenta o processo de imaginação. O segundo subcorpus - "Estresse-Coping", foi formado pela classe 1 - Processo de Enfrentamento da Dor, classe 2 - Técnicas para Controle do Estresse e classe 3 - Processo de Avaliação e Intervenção. Estas classes se relacionam por incluírem os processos de enfrentamento da dor, as técnicas para o controle do estresse e o processo de avaliação e intervenção. Os dados foram novamente divididos em um novo subcorpus novamente, opondo a classe 1 às classes 2 e 3 . Os conteúdos em cada uma das escalas são apresentados na Figura 3.

Na primeira partição, a classe 4 , parte do corpus "Intervindo no coping da dor", denominada de "Processos da Imaginação", foi respon- 


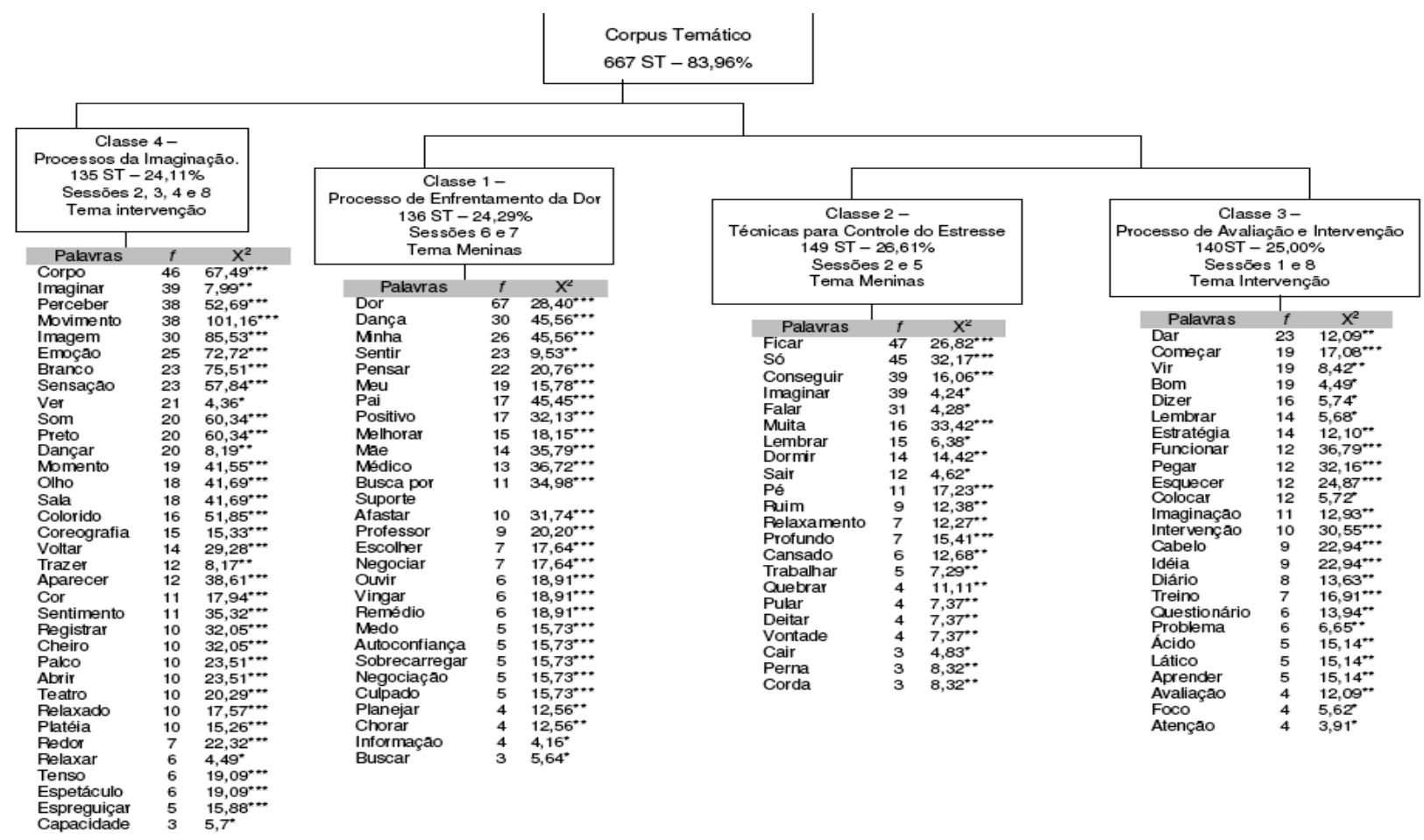

Figura 3. Análise dos relatos da mediadora e bailarinas durante programa de intervenção no coping da dor pelo método de Classificação Hierárquica Descendente.

Nota: ${ }^{*} p<0,05 ; * *<<0,01 ; * *<<0,0001$, teste Qui-Quadrado, software IRAMUTEQ.

sável por $24,11 \%$ dos segmentos de texto. Os principais elementos relacionados a esta classe foram: movimento, imagem, branco, preto, emoção, corpo, sensação, colorido, sentimento, registrar, cheiro, palco, teatro, tenso, relaxado, espetáculo, cor, coreografia, plateia, capacidade, dançar, entre outros (Figura 3). O conteúdo desta classe retrata o processo utilizado para imaginar, que utiliza da percepção sensorial, envolvendo todos os sentidos, visão, olfato, tato, audição, paladar, além, da percepção das sensações, emoções e sentimentos, que surgem ao imaginar determinada situação. Os trechos a seguir ilustram esse contexto:

"Você percebe que todo mundo que estava ao redor reparou que você errou, qual é a sensação que dá fazer esse movimento errado na frente de todo mundo" (S8);

"A imagem é colorida ou preta e branca? É nítida ou não? Como é fazer essa movimentação? Que emoções aparecem ao participar desse festival e fazer as coisas muito bem?" (S8);

"Tem som? Tem cheiro? Que emoção aparece de estar pisando nesse palco? Surge algum sentimento? Uma sensação boa ou ruim ensaiar agora nesse palco? Você está sozinho ou tem mais pessoas com você?" (S3).

Opostamente a ela, a classe 1, incluída no corpus "Estresse-coping", chamada de "Processo de Enfrentamento da Dor", foi responsável por $24,29 \%$ dos segmentos de texto. Os principais elementos que se relacionaram a esta classe foram: dança, pai, mãe, médico, busca por suporte, positivo, afastar, dor, professor, ouvir, vingar, remédio, melhora, negociar, medo, autoconfiança, sobrecarregar, culpado, planejar, chorar, sentir, buscar, informação, entre outras (Figura 3). O conteúdo desta classe trata principalmente sobre as possíveis estratégias de enfrentamento da dor, sendo elas positivas e negativas, qual a avaliação prévia cognitiva para a utilização das mesmas, o que influencia na escotha de qual estratégia utilizar, e as repercussões que elas provocam. Os trechos a seguir ilustram esse contexto:

"Se você chegou chorando de dor e mãe ou pai associar com dança, é óbvio que a ameaça vai vir um momento ou outro, ela vai vir e dizer eu vou te tirar da dança, e então cabe negociar" (S7); 
"Medo de não conseguir dançar, medo de se machucar de verdade, medo do que pode acontecer... penso em adiar a ida ao médico para continuar dançando... aquela sensação que se você for no médico ele vai dizer pare de dançar porque é a única solução" (S5);

"Você precisa fazer algo contra isso que não deu certo, e não apenas dizer eu desisto, você pode ter autoconfiança e pensar que tudo vai passar, que tudo vai dar certo" (S7);

Em outra partição, a classe 2, parte do corpus "Estresse-coping", chamada de "Técnicas para Controle do Estresse", foi responsável por $26,61 \%$ dos segmentos de texto. Os principais elementos que se relacionaram a esta classe foram: pé, conseguir, profundo, dormir, cansado, ruim, relaxamento, quebrar, ficar, só, perna, pular, corda, deitar, vontade, trabalhar, lembrar, cair, sair, falar, imaginar, entre outros (Figura 3). O conteúdo desta classe retrata o relaxamento e a imaginação como técnicas para controle do estresse, e para reduzir o estressor dor, presente no cotidiano das bailarinas. Os trechos a seguir ilustram esse contexto:

"A dor foi diminuindo, diminuindo e a dor sumiu. Eu consegui! Parecia que eu estava me distanciando, sabe quando parece que ela vai indo, e ela foi mudando de cor e de forma e parecia que eu fui me distanciando da dor quando você foi falando isso" (S5);

"A distração é uma boa estratégia, o pular corda da semana passada que vocês ficaram tão empolgadas é uma estratégia de distração" (S7);

"Quando você trabalha com a respiração junto ajuda muito a relaxar e só o próprio fato de relaxar, às vezes, já ajuda a diminuir a dor" (S2);

E opostamente a ela, a classe 3, incluída no corpus "Estresse-coping", chamada de "Processo de Avaliação e Intervenção", foi responsável por $25,00 \%$ dos segmentos de texto. Os principais elementos relacionados a esta classe foram: intervenção, esquecer, cabelo, ideia, começar, treino, ácido, lático, aprender, questionário, diário, imaginação, estratégia, avaliação, problema, foco, atenção, entre outros (Figura 3). O conteúdo desta classe demonstra as medidas psicofisiológicas da dor (análises bioquímicas com o cabelo e sangue; diário da dor e questionários), assim como o processo de intervenção, que incluiu relaxamento, imaginação, aprendizagem sobre as estratégias de enfrentamento, com sessões de psicoeducação. Os trechos a seguir ilustram esse contexto:

"Eu gostei bastante da intervenção, mas sem cortar o cabelo" (S8);

"É o treino de imaginação, vamos começar com coisas simples, e depois a gente vai dificultando, mas, vamos por partes" (S1);

"O ácido lático é o que eu medi com o furo no dedo, aqui lá é para avaliar o ácido lático, que é uma substância química que libera no corpo quando você faz muito exercício, e aquilo lá em excesso é o que dá dor" (S5).

Analisando o dendograma e o conteúdo obtido pela análise temática (Figura 3) verifica-se o processo de avaliação da dor, através de questionários, diário da dor, medidas psicofisiológicas, assim como o processo de intervenção, que inclui técnicas para controle do estresse, como relaxamento; estratégias de enfrentamento da dor, acompanhadas de uma psicoeducação para distinção de estratégias adaptativas e mal adaptativas; e treino de imaginação, incluindo todo o processo sensorial dessa intervenção. Além disso, foi realizada a Análise de Similitude, apresentada na Figura 4.

É interessante observar, pela Análise de Similitude, a interconexão entre as palavras, bem como o nível de relação entre elas, tendo em vista que o índice de coocorrências entre as palavras podem ser mais fortes ou mais fracos (teste do Qui-Quadrado). Assim, pela Análise de Similitude, é possível verificar a forte relação da dor, palavra central, com ensaio, técnica, exercicio, controle, problema. Isso faz bastante sentido já que o exercício, a técnica, os ensaios e o manter o controle trazem como problema a dor. No mesmo espaço gráfico, estão os sentimentos de medo, raiva, a própria palavra sentir, assim como estratégia e autoconfiança. Assim, percebe-se que a dor gera nessas bailarinas medo e raiva, sentimentos esses que precisam ser trabalhados para que não haja uma catastrofização da dor; para isso, pode-se utilizar da estratégia de enfrentamento adaptativa de Autoconfiança. 


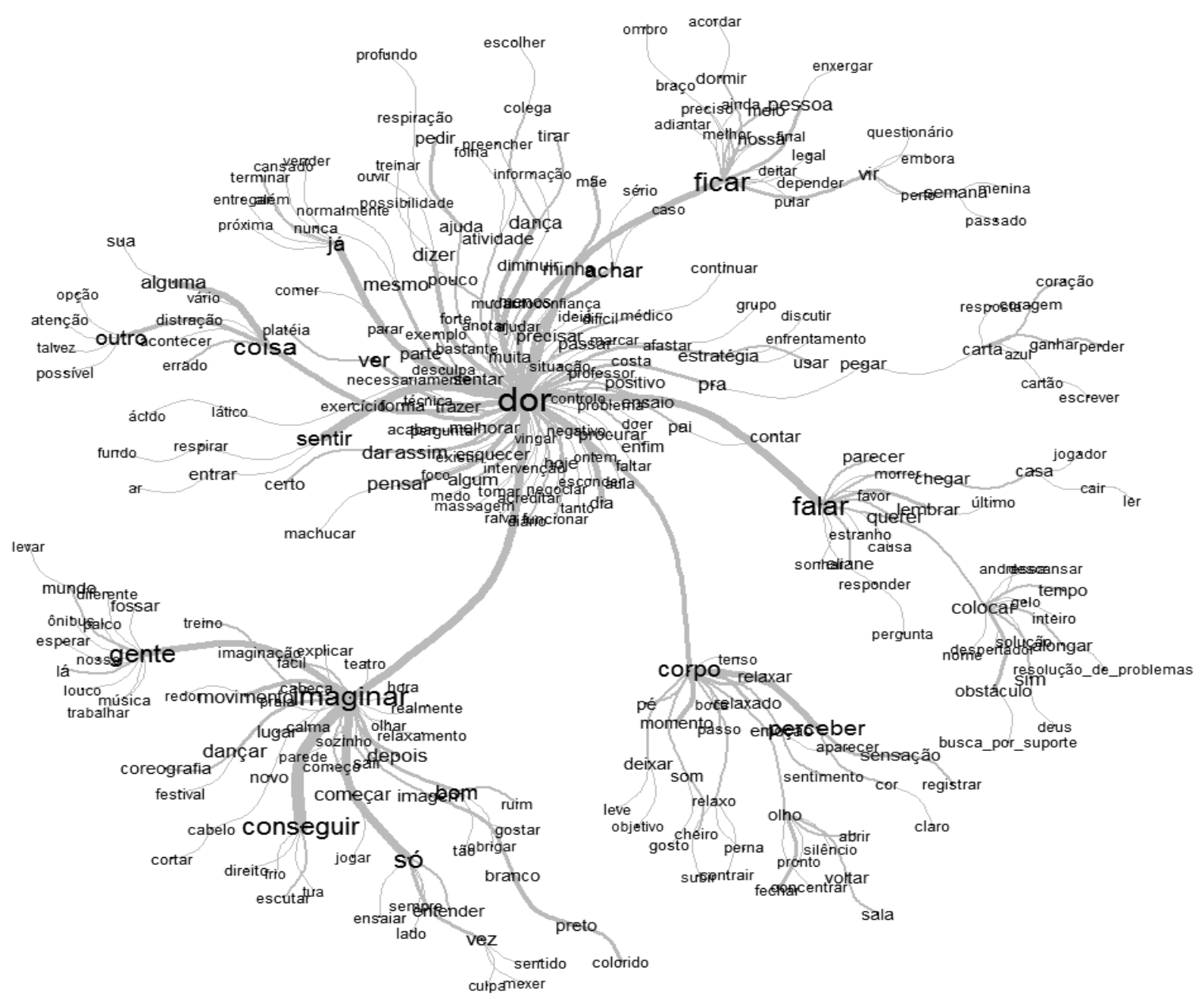

Figura 4. Análise de Similitude da análise temática dos relatos das bailarinas e da mediadora durante programa de intervenção no coping da dor.

Também estão próximas as palavras professor, esquecer, massagem e médico (Figura 4). Considerando que as bailarinas não tentam negociar com o professor por treinos mais leves, e não procuram um médico quando estão com dor, porque se sentem ameaçadas; isso intensifica a sensação de dor, e psicologicamente as funções básicas de autonomia e competência permanecem ameaçadas. Mãe e colega permanecem mais distantes, assim como platéia, distração e atenção, já a palavra pai encontra-se mais próxima da palavra dor, lembrando que o software IRAMUTEQ considera as combinações de palavras, portanto, nesse caso, quis dizer pais, ou seja, a combinação de pai e mãe está mais vinculada à dor, do que apenas a figura materna. Há traços fortes que conectam a palavra dor a: ficar, falar (que por sua vez relaciona-se a querer, lembrar, resolução de problemas, obstáculo, solução, alongar e despertador), corpo (este relacionado a perceber, sensação, sentimento, relaxar), imaginar (relacionado a conseguir, dançar, coreografia, festival, sozinho), e, por fim, com sentir (relacionado com respirar fundo; Figura 4).

\section{Discussão}

Este estudo tem um caráter metodológico, procurando mostrar as possibilidades de análise do conteúdo de uma intervenção psicológica voltada para a promoção do coping da dor em bailarinas, de forma a apreender as ações verbais das participantes e da psicóloga que conduziu esse processo de mediação de aprendizagem. Os relatos verbais ocorridos durante a intervenção foram, então, analisados pelo software IRAMUTEQ (Camargo \& Justo, 2013, 2015). 
Com este software, foi possível identificar, pelas representações gráficas dos relatos verbais da mediadora, uma forte ênfase da dor em suas relações com os ensaios e as aulas, o ácido lático, a dança, também com o corpo, bem como a autopercepção e as sensações e emoções associadas ao contexto. Este conteúdo está presente em alguns estudos nacionais (Almeida \& Flores-Pereira, 2013; Meereis, Teixeira, Pranke, Lemos, \& Mota, 2013) e internacionais (Cahalan et al., 2015; Jacobs, Hincapié, \& Cassidy, 2012; McEven \& Young, 2011; Wyon \& Koutedakis, 2013), o que reforça a importância desse tipo de proposta de intervenção. Além disso, as estratégias de enfrentamento relacionam-se fortemente com o conseguir imaginar.

No conjunto dos dados das bailarinas, destacaram-se as palavras distrair e o negociar, os quais também se associaram fortemente à dor. A estratégia de enfrentamento de distração é bastante frequente nessa população e faixa etária (Skinner \& Zimmer-Gembeck, 2007). Este comportamento é classificado na família de $\mathrm{Co}$ ping de Acomodação, sendo indicativo de uma percepção do estressor como um desafio e não uma ameaça à necessidade básica de Autonomia, segundo a Teoria Motivacional do Coping (Skinner et al., 2003; Skinner \& Wellborn, 1994). Contudo, a estratégia de enfrentamento de negociação, que pertence à mesma família de coping de Acomodação (Skinner et al., 2003), no caso das bailarinas, tem uma função menos adaptativa, pois estas apresentam dificuldades de negociar com o professor. As tentativas de negociação para diminuir a intensidade ou frequência dos exercícios quando se está com dor pode resultar em afastamento do grupo de dança, o que acaba sendo percebido como pior do que estar com dor. Pensando não apenas no contexto dança, mas também no período de desenvolvimento que as bailarinas se encontram a adolescência - Compas et al. (2012) afirmam que estratégias de controle secundário, como a distração, se associa a um melhor ajustamento de crianças e adolescentes. Em contexto de dor durante a hospitalização, Motta et al. (2015) identificaram a distração como uma estratégia de enfrentamento adaptativa bastante utilizada por crianças e adolescentes. Portanto, a estratégia de enfrentamento de distração frente à dor pode ser incentivada com as bailarinas, enquanto que a negociação deveria ser mais bem estudada, já que, nesse contexto, apresenta uma função psicológica diferente da proposta teoricamente. Nessa mesma direção, os dados mostraram uma forte relação inversa entre dor e médico, o mesmo ocorrendo com o professor. Estes não são vistos, portanto, como uma fonte de suporte social no enfrentamento da dor. A busca de suporte social em situação de dor é mais frequente com os colegas, mas também se relaciona com o compartilhar (ou não compartilhar) com mãe e pai o fato de estar com dor, seguindo o padrão típico da adolescência, em que o grupo social tende a ter uma influência grande (Zimmer-Gembeck \& Skinner, 2011).

Foi possível caracterizar um padrão de estratégias de enfrentamento relacionadas - Autoconfiança, Busca de Informação, Acomodação e Distração - todas relacionadas à percepção do estressor como um desafio e ao desfecho mais positivo ao longo prazo (Skinner et al., 2003). Entretanto, estas não estão próximas de estratégias de enfrentamento voltadas para a Resolução de Problemas, que inclui o alongamento, e a Busca de Suporte. Nesse sentido, o excesso de autoconfiança e a acomodação ao estressor, por meio da distração, por exemplo, podem aumentar o risco para a saúde, considerando que a dor é um sinal de alerta. Nesse sentido, deve-se avaliar o repertório de enfrentamento do adolescente nesse contexto de risco para a saúde, pois, segundo Jacobs, Hincapié e Cassidy (2012), o tipo de estratégia de enfrentamento apresentada pelos bailarinos pode influenciar na freqüência e intensidade da dor e/ou lesão.

Lidar com a dor de forma indireta, sem enfrentar o estressor - o excesso de exercícios físicos - e sem buscar suporte social com os adultos (professores e pais) compõe uma situação de risco, a qual é percebida pelas bailarinas, pois a dança associou-se com a palavra medo e com as características da dor, imaginadas na Sessão 5 da intervenção. Evidencia-se o quanto a dor representa uma ameaça à competência para dançar e à sua autonomia, a ponto de gerar medo. 
Reafirma esta condição o fato das palavras falar e chorar estarem associadas. Parece positivo o fato da intervenção, que usou a técnica de imaginação, ter gerado associações entre imaginar, ensaio e planejar, sugerindo um conjunto de estratégias de enfrentamento mais adaptativas no médio e longo prazo. Segundo a análise temática feita pelo software IRAMUTEQ, as palavras de maior destaque na intervenção foram: dor, corpo, conseguir, imaginar, dançar, sentir, dança, ficar, falar, perceber. Assim, é possível verificar uma lógica psicológica funcional para a Análise de Similitude, demonstrando sua exequibilidade e precisão.

Em termos metodológicos, o software IRAMUTEQ, que é comumente utilizado para análise de entrevistas para verificação das representações sociais, demonstrou-se pertinente, fidedigno e útil para a análise de intervenções psicológicas em grupo. Essa proposta de análise do conteúdo verbal em contexto interativo reduz o tempo de trabalho do pesquisador, que antes gastava muito tempo para fazer a análise de conteúdo, além de diminuir os erros provocados pela subjetividade do pesquisador ao realizar os agrupamentos em classes. Assim, criam-se categorias precisas, considerando a frequência das palavras utilizadas, bem como em qual contexto elas se apresentam, o nível de relação entre elas, mensurado pelo Qui-Quadrado e nível de significância, além de apresentar materiais gráficos que facilitam a visualização do conteúdo analisado.

Algumas limitações precisam ser consideradas. Após agrupamento das palavras em classes, cabe ao pesquisador dar um significado a essa classe gerada. Assim, o pesquisador precisa ter um conhecimento aprofundado do tema para nomear a categoria mais ampla, que enquadra todos os componentes respectivos aquela determinada classe. Além disso, há um trabalho árduo para a construção do corpus, sendo que o conteúdo transcrito precisa ser transformado em corpus para poder ser analisado. Qualquer erro de codificação nas linhas de comando, o software não processa a análise, cabendo ao pesquisador identificar o erro e corrigi-lo. Da mesma forma, os erros de português não são interpretados pelo software, assim como palavras coloquiais, ca- bendo ao pesquisador alterar as falas de forma que fiquem mais científicas, porém, sem alterar o sentido da fala da pessoa. É válido ressaltar que o software é uma ferramenta, um recurso para auxiliar o pesquisador na análise. Sozinha, essa ferramenta não compreende, mas apenas categoriza as frases a partir de códigos. Posteriormente, refletindo sobre esses códigos, o pesquisador realiza a análise propriamente dita.

Apesar dessas características, o software garante resultados precisos, sem interferências subjetivas do pesquisador, com a vantagem de ser internacionalmente utilizado. Como esta é uma das primeiras pesquisas utilizando o software para análise de intervenção, recomenda-se que novas pesquisas sejam realizadas, com diferentes populações, a fim de assegurar que o método apresenta estabilidade ao ser empregado em outras pesquisas. Este cuidado é relevante, especialmente frente à falta de programas de intervenção psicológicas no país, seja no coping, em bailarinos, com adolescentes, em grupo e, em particular, na dor.

\section{Referências}

Alcântara, T. V., Shioga, J. E. M., Lima, M. J. V., Lage, A. M. V., \& Maia, A. H. N. (2013). Intervenções psicológicas na sala de espera: Estratégias no contexto da oncologia pediátrica. Revista da Sociedade Brasileira de Psicologia Hospitalar, 16(2), 103-119. Recuperado em pepsic.bvsalud.org/scielo.php?script=sci_arttext \&pid $=$ S1516-08582013000200008

Almeida, D. D. D., \& Flores-Pereira, M. T. (2013). As corporalidades do trabalho bailarino: Entre a exigência extrema e o dançar com a alma. Revista de Administração Contemporânea, 17(6), 720-738. Recuperado em http://www.anpad.org. $\mathrm{br} / \mathrm{rac}$

Andersen, M. B. (2011). Aspectos abrangentes da psicologia do esporte. In J. L. van Raalte, \& B. W. Brewer (Eds.), Psicologia do Esporte (2. ed., T. B. Hildegard, Trad., pp. 13-23). São Paulo, SP: Santos.

Cahalan, R., O'Sullivan, P., Purtill, H., Bargary, N., Ni Bhriain, O., \& O'Sullivan, K. (2015). Inability to perform because of pain/injury in elite adult Irish dance: A prospective investigation of contributing factors. Scandinavian Journal 
of Medicine \& Science in Sports, online. doi:10.1111/sms.12492

Camargo, B. V., \& Justo, A. M. (2013). IRAMUTEQ: Um software gratuito para análise de dados textuais. Temas em Psicologia, 21(2), 513518. doi:10.9788/TP2013.2-16

Camargo, B. V., \& Justo, A. M. (2015). Tutorial para uso do software IRAMUTEQ. Recuperado em http://www.laccos.com.br/index. php?option $=$ com_content\&view $=$ article\&id $=2$ 08\%3Atutorial-do-software-iramuteq-em-portu gues \&catid $=40 \% 3$ Aoutros \&Itemid $=9 \&$ lang $=$ br

Caudill, M. A. (1998). Controle a dor antes que ela assuma o controle: Um programa clinicamente comprovado (D. M. Bolagnol, Trad.). São Paulo, SP: Summus.

Chaves, C., Vásquez, F., \& Hervás, G. (2015). Positive interventions in seriously-ill children: Effects on well-being alter granting a wish. Journal of Health Psychology, 29(1). doi:10.1177/1359105314567768

Compas, B. E., Jaser, S. S., Dunn, M. J., \& Rodriguez, E. M. (2012). Coping with chronic illness in childhood and adolescence. Annual Review of Clinical Psychology, 8, 455-480. doi:10.1146/ annurev-clinpsy-032511-143108

Encarnación, M. L. G., Meyers, M. C., Ryan, N. D., $\&$ Pease, D. G. (2000). Pain coping styles of ballet performers. Journal of Sport Behavior, 23(1), 20-32. Recuperado em https://www.thefreelibrary.com/Pain+Coping + Styles + of + Ballet+Perf ormers.-a061909294

Godtsfriedt, J., Andrade, A., \& Vasconcellos, D. I. C. (2014). Treinamento mental no tênis: Revisão sistemática da literatura. Revista Brasileira de Ciências do Esporte, 36(2), 577-586. doi:10.1590/S0101-32892014000200020

Gould, D., Damarjian, N., \& Greenleaf, C. (2011). Treinamento imaginário para a maximização do desempenho. In J. L. Raalte \& B. W. Brewer (Eds.), Psicologia do Esporte (2. ed., T. B. Hildegard, Trad., pp. 49-74). São Paulo, SP: Santos.

Guarino, L. (2015). Is dance a sport? A twenty-firstcenturydebate.JournalofDanceEducation, 15(2), 77-80. doi:10.1080/15290824.2015.978334

Heaney, C. A., Walker, N. C., Green, A. J. K., \& Rostron, C. L. (2015). Sport psychology education for sport injury rehabilitation professionals: A systematic review. Physical Therapy in Sport, 16(1), 72-79. doi:10.1016/j.ptsp.2014.04.001
Jacobs, C. L., Hincapié, C. A., \& Cassidy, J. D. (2012). Musculoskeletal injuries and pain in dancers: A systematic review update. Journal of Dance Medicine \& Science, 16(2), 74-84. doi:10.1016/j.apmr.2008.02.020

Larsen, C. H., \& Henriksen, K. (2015). Psyhological momentum in team sport: An intervention program in professional soccer. Sport Science Review, 24(1-2), 27-39. doi:10.1515/ssr-20150007

Leandro-França, C., Murta, S. G., \& Villa, M. B. (2014). Efeitos de uma intervenção breve no planejamento para a aposentadoria. Revista Psicologia, Organizações e Trabalho, 14(3), 257-270. Recuperado em pepsic.bvsalud.org/scielo.php?script $=$ sci_arttext\&pid $=$ S1984-66572014000300002

Lino, R. L., \& Ziliotto, D. M. (2013). Possibilidades da psicologia do trabalho nas organizações: Relato de experiência em indústria calçadista. Revista Psicologia em Foco, 5(5), 5-21. Recuperado em pepsic.bvsalud.org/scielo.php?script=sci_arttext \&pid $=$ S1808-42812010000200008

Lipp, M. E. N. (2012). Bases teóricas da Psicoterapia Cognitivo-Comportamental. In M. E. N. Lipp \& E. M. P. Yoshida (Ed.), Psicoterapias breves nos diferentes estágios evolutivos (Cap. 1). São Paulo, SP: Casa do Psicólogo.

Lopes, J., \& Almeida, L. S. (2015). Questões e modelos de avaliação e intervenção em Psicologia Escolar: O caso da Europa e América do Norte. Estudos de Psicologia (Campinas), 32(1), 7585. doi:10.1590/0103-166X2015000100007

Markland, D., Hall, C. R., Duncan, L. R., \& Simatovic, J. (2015). The effects of an imagery intervention on implicit and explicit exercise attitudes. Psychology of Sport and Exercise, 17(1), 24-31. doi:10.1016/j.psychsport.2014.11.007

Martens, R. (1987). Coaches guide to Sport Psychology. Champaign, IL: Human Kinectics.

McEven, K., \& Young, K. (2011). Ballet and pain: Reflections on risk-dance culture. Qualitative Research in Sport, Exercise and Health, 3(2), 152-173. doi:10.1080/2159676X.2011.572181

Meereis, E. C. W., Teixeira, C. S., Pranke, G. I., Lemos, L. F. C., \& Mota, C. B. (2013). Sintomatologia dolorosa em bailarinos: Uma revisão. Revista Brasileira de Ciência e Movimento, 21(2), 143-150. doi:10.18511/0103-1716/rbcm. v21n2p143-150 
Motta, A. B., \& Enumo, S. R. F. (2010). Intervenção psicológica lúdica para o enfrentamento da hospitalização para crianças com câncer. Psicologia: Teoria e Pesquisa, 26(3), 445-454. doi:10.1590/S0102-37722010000300007

Motta, A. B., Perosa, G. B., Barros, L., Silveira, K. A., Lima, A. S. S., Garnier, L. E., ...Caprini, F. R. (2015). Comportamentos de coping no contexto da hospitalização infantil. Estudos de Psicologia (Campinas), 32(2), 331-341. doi:10.1590/0103$-166 \times 2015000200016$

Pfeifer, P. M., \& Ruschel, P. P. (2013). Preparo psicológico: A influência na utilização de estratégias de enfrentamento pós-transplante cardíaco. Revista da Sociedade Brasileira de Psicologia Hospitalar, 16(2), 153-165. Recuperado em pepsic.bvsalud.org/scielo.php?script=sci_arttext \&pid=S1516-08582013000200011

Ramos, F. P. (2012). Uma proposta de análise do coping no contexto de grupo de mães e bebês prematuros e com baixo peso na Unidade de Terapia Intensiva Neonatal (Tese de doutorado não publicada, Programa de Pós-Graduação em Psicologia, Universidade Federal do Espírito Santo, Vitória, ES, Brasil).

Ramos, F. P., Enumo, S. R. F., \& Paula, K. M. P. (2015). Teoria Motivacional do Coping: Uma proposta desenvolvimentista de análise do enfrentamento do estresse. Estudos de Psicologia (Campinas), 32(2), 269-279. doi:10.1590/0103$-166 \times 2015000200011$

Retinaud, P., \& Marchand, P. (2012). Application de la méthode ALCESTE aux $<<$ gros $>>$ corpus et stabilité des $<<$ mondes lexicaus $>>$ : analyse du $<<$ CableGate $>>$ avec IRAMUTEQ. In Actes des 11eme Journées internationales d'Analyse statistique des Données Textuelles (pp. 835-844). Liège, Belgique.

Singh, S. (2011). The meaning of pain during the process of embodiment: A case study of trainee modern dancer's experiences of pain. Sport, $E d$ ucation \& Society, 16(4), 451-465. doi:10.1080/ 13573322.2011 .589643

Skinner, E. A., Edge, K., Altman, J., \& Sherwood, H. (2003). Searching for the structure of coping: A review and critique of category systems for classifying ways of coping. Psychological Bulletin, 129(2), 216-269. doi:10.1037/00332909.129.2.216

Skinner, E. A., \& Welborn, J. G. (1994). Coping during childhood and adolescence: A motivacional perspective. In D. L. Featherman, R. M. Lerner, \& R. M. M. Perlmutter (Eds.). Life-Span Development and Behavior (pp. 91-133). Hillsdale, NJ: Lawrence Erlbaum Associates.

Skinner, E. A., \& Zimmer-Gembeck, M. J. (2007). The development of coping. Annual Review of Psychology, 58(1), 119-144. doi:10.1146/annurev.psych.58.110405.085705

Souza, M. P. R., Ramos, C. J. M., Lima, C. P., Barbosa, D. R., Calado, V. A., \& Yamamoto, K. (2014). Atuação do psicólogo na educação: Análise de publicações científicas brasileiras. Psicologia da Educação, 38(1), 123-138. Recuperado em pepsic.bvsalud.org/scielo.php?script $=$ sci_ arttext\&pid=S1414

Stefanello, J. M. F. (2007). Treinamento de competências psicológicas: Em busca da excelência esportiva. Barueri, SP: Manole.

Vealey, R. S. (1991). Entrenamiento en imaginación para el perfeccionamiento de la ejecución. In J. M. Williams (Eds.). Psicología aplicada al deporte (pp. 308-344). Biblioteca Nueva.

Vieira, L. F., Vieira, J. L. L., \& Nascimento, J. R. A., Jr. (2013). O estado da arte da pesquisa em Psicologia do Esporte no Brasil. Revista de Psicologia del Deporte, 22(2), 501-507. Recuperado em www.redalyc.org/pdf/2351/235128058020.pdf

Weinberg, R., \& Gould, D. (2014). Foundations of Sport and Exercise Psychology (6. ed.). Champaign, IL: Human Kinectics.

Wright, J. H., Sudack, D. M., Turkington, D., \& Thase, M. C. (2012). Terapia Cognitivo-Comportamental de alto rendimento para sessões breves (G. W. Linck \& M. G. Armando, Trads.). Porto Alegre, RS: Artmed.

Wyon, M. A., \& Koutedakis, Y. (2013). Muscular fatigue: Considerations for dance. Journal of Dance Medicine \& Science, 17(2), 63-69. doi:10.12678/1089-313X.17.2.63

Zimmer-Gembeck, M. J., \& Skinner, E. A. (2011). The development of coping across childhood and adolescence: An integrative review and critique of research. International Journal of Behavioral Development, 35 (1), 1-17. doi:10.1177/0165025410384923 